Tohoku J. Exp. Med., 2006, 209, 329-336

\title{
High Prevalence of Gastroesophageal Reflux Disease with Minimal Mucosal Change in Asthmatic Patients
}

\author{
Yasuo Shimizu, Kunio Dobashi, ${ }^{1}$ Setsuo Kobayashi, ${ }^{2}$ Ichiro OhKi, ${ }^{2}$ \\ Masahiko Tokushima, ${ }^{2}$ Motoyasu Kusano, Osamu Kawamura, \\ Yasuyuki Shimoyama, Mitsuyoshi Utsugi and Masatomo Mori \\ Department of Medicine and Molecular Science, Gunma University Graduate \\ School of Medicine, Gunma, Japan, \\ ${ }^{I}$ Gunma University Faculty of Health Science, Gunma, Japan, and \\ ${ }^{2}$ Maebashi North Hospital, Gunma, Japan
}

\begin{abstract}
Shimizu, Y., Dobashi, K., Kobayashi, S., Ohri, I., Tokushima, M., Kusano, M., Kawamura, O., Shimoyama, Y., Utsugi, M. and Mori, M. High Prevalence of Gastroesophageal Reflux Disease with Minimal Mucosal Change in Asthmatic Patients. Tohoku J. Exp. Med., 2006, 209 (4), 329-336 — It is known that the prevalence of gastroesophageal reflux disease (GERD) in asthmatic patients is high. Although an endoscopic diagnosis of GERD based on the established Los Angeles (LA) classification requires the detection of erosive mucosal breaks, there are patients with GERD who have prominent erythema of the esophageal membrane without erosive mucosal breaks. Non-erosive mucosal change denotes the minimal change of the discoloring type of reflux esophagitis. This study was undertaken to determine the prevalence of GERD in asthmatic patients using the LA classification with the inclusion of minimal change, compared to the prevalence determined using the established LA classification without minimal change. The presence of GERD in asthmatic patients $(n=78)$, non-asthmatic disease control patients $(n=56)$, and healthy subjects $(n=150)$ was evaluated by endoscopic examination. The frequency of GERD in asthmatic patients based on the LA classification with minimal change was higher (54/78, $69.2 \%)$ than in asthmatic patients based on the LA classification without minimal change $(37 / 78,47.4 \%)(p<0.05)$. The prevalence of GERD in asthmatic patients $(69.2 \%)$ was higher than that in disease control patients $(17 / 56,30.4 \%)$ and healthy subjects $(27 / 150$, $18.0 \%$ ) based on the LA classification with minimum change. These data indicate that asthmatic patients have a high frequency of GERD. In addition, without the inclusion of minimum change to the diagnosis of GERD, the prevalence of GERD appears to be underestimated in asthmatic patients. Therefore, physicians should carefully observe asthmatic patients with minimal change on endoscopy. —— asthma; gastroesophageal reflux disease; minimal change; Los Angeles classification; endoscopic examination (C) 2006 Tohoku University Medical Press
\end{abstract}

Received April 17, 2006; revision accepted for publication June 5, 2006.

Correspondence: Yasuo Shimizu, M.D., Ph.D., Department of Medicine and Molecular Science, Gunma University Graduate School of Medicine, 3-39-15 Showa-machi, Maebashi, Gunma 371-8511, Japan.

e-mail: yasuos@med.gunma-u.ac.jp 
Gastroesophageal reflux disease (GERD), which is regurgitation of acid to the esophagus, has been proposed as a triggering factor for asthma (Harding 2003a, b). Airway pH deviation by GERD-induced acid exposure is considered to be a factor for inducing inflammatory cell activation (Ricciardolo et al. 2004) and the inflammatory change-mediated neural imbalance may result in airway hyperresponsiveness, a feature of asthma (Ichinose 2003). Although the efficacy of acidsuppressive drugs on asthmatic patients with GERD is controversial, prevention of acid exposure of the airway has been considered to lead asthma improvement in asthmatic patients with GERD. Recently, it has been reported that treatment for GERD using the acid-suppressive drugs esomeprazole or lansoprazole, which are proton pump inhibitors (PPIs), improved asthma symptoms (Kiljander et al. 2006; Shimizu et al. 2006). The symptoms of GERD are chest or stomach discomfort, heartburn, and liquid returning to the throat or mouth (Carlsson et al. 1998). The diagnosis of GERD can be established from questionnaires about these symptoms, such as the questionnaire for the diagnosis of reflux disease (QUEST) (Carlsson et al. 1998), 24-h pH measurement in the esophagus (Harding et al. 1999), and endoscopic examination (Armstrong et al. 1996). Each of these diagnostic methods (questionnaires, 24-h pH measurement, and endoscopic examination) has advantages and disadvantages. For example, 24-h pH measurement has a higher sensitivity for acid regurgitation (DeVault and Castell 1995) than endoscopic examination, but endoscopic examination has the benefit of allowing direct observation of acid stress-induced esophageal mucosal injuries and the existence of a hiatal hernia, as well as the ability to exclude GERD caused by esophageal cancer (Armstrong et al. 1996). Such differences in the methods used to diagnose GERD result in different determinations of the prevalence of GERD in asthmatic patients. Endoscopic evaluation of GERD prevalence using grades $\mathrm{N}$ to $\mathrm{D}$ might minimize the differences in the GERD prevalence reports in asthmatic patients found with other validation methods of higher sensitivity.
The established Los Angeles (LA) classification of grades A to D is based on endoscopic evaluation of esophageal erosive mucosal breaks (Lundell et al. 1999). Endoscopic examination interpretation based on the established LA classification was used in a randomized trial of medical therapy and surgical anti-reflux therapies to study the long-term asthma outcome (Sontag et al. 2003). Although the established LA classification is based on the extent of the apparent erosive mucosal breaks of grades A to D, it does not include grade $\mathrm{M}$, which denotes the non-erosive minimal mucosal change (Kiesslich et al. 2004; Nakamura et al. 2005) of the "discoloring" type of reflux esophagitis (Hoshihara and Hashimoto 2000; Shimoyama et al. 2005). This minimal change is caused by acid contacting the esophageal mucosa; on-demand $\mathrm{H}_{2}$ receptor blockers $\left(\mathrm{H}_{2}\right.$-blockers), which have less effect of acid suppression than PPIs, were reported to be suitable for treating minimal change in GERD (Nakamura et al. 2005). Because the acid reflux in grade $M$ requires treatment with acid-suppressive drugs, it is possible that grade $\mathrm{M}$ of GERD is underlying the pathogenesis of asthma deterioration and the diagnosis of grade M of GERD may be useful for treating asthmatic patients with GERD. There are no studies about the prevalence of GERD in asthmatic patients using the LA classification including grade $\mathrm{M}$.

The aim of the present study was to determine the prevalence of GERD in asthmatic patients based on the LA classification including the esophageal mucosal minimal change. In this study, we first examined the prevalence of GERD in asthmatic patients on endoscopic examination using the LA classification with the addition of grade $\mathrm{M}$, defined as minimal change of the esophageal mucosa. The GERD prevalence determined in this manner was compared to the prevalence of GERD determined by the established LA classification without grade M and the QUEST score.

\section{Methods and Study Design}

\section{Evaluation of GERD}

The diagnosis of GERD was made by endoscopic examination using the established LA classification 
(Armstrong et al. 1996). The established LA classification defines the changes of an esophageal mucosal break as an erosive area of slough or erythema clearly demarcated from adjacent normal-appearing mucosa. The established LA classification divides GERD state into four grades of $\mathrm{A}$ to $\mathrm{D}$, with grade $\mathrm{D}$ the most severe, as follows: grade $\mathrm{A}$, a mucosal break $\leqq 5 \mathrm{~mm}$ in length; grade $\mathrm{B}$, a mucosal break $>5 \mathrm{~mm}$ in length; grade $\mathrm{C}$, a mucosal break continuous between $>2$ folds; grade $\mathrm{D}$, a mucosal break $\geqq 75 \%$ of the esophageal circumference. It has been reported that there is a large number of patients with GERD that is below grade A and labeled as grades $\mathrm{N}$ and $\mathrm{M}$ (Hoshihara and Hashimoto 2000; Nakamura et al. 2005). Grade $\mathrm{N}$ is defined as no apparent mucosal changes. Grade $\mathrm{M}$ (minimal change) is defined by the presence of prominent erythema without clear demarcation or whitish cloudiness of the lower esophageal mucosa obscuring the longitudinal blood vessels. In this study, all enrolled patients were classified as grades $\mathrm{N}$ to $\mathrm{D}$ by endoscopic findings, and grades $\mathrm{M}$ to $\mathrm{D}$ were diagnosed as GERD. The diagnosis of GERD was made by four physicians specializing in endoscopy using the same equipment (GIF Q-240, Olympus Optical, Tokyo). The QUEST score, which has been proven to be useful in the assessment of GERD, was used to assess GERD prevalence. The QUEST score was derived from seven questions about stomach or chest discomfort in various situations and liquid returning to the throat or mouth. A QUEST score $\geqq 4$ was diagnostic of GERD (Carlsson et al. 1998).

\section{Subjects}

A total of 284 subjects (129 men and 155 women, with a mean age of $55.2 \pm 16.7$ years) underwent endoscopic examination. Based on the endoscopic examination, 78 asthmatic patients ( 33 men and 45 women, mean age $58.9 \pm 17.6$ years), 56 non-asthmatic disease control patients (23 men and 33 women, mean age $55.7 \pm 12.1$ years), and 150 healthy subjects ( 73 men and 77 women, mean age $=52.3 \pm 21.3$ years) were graded from $\mathrm{N}$ to $\mathrm{D}$ using the LA classification with minimum change. The disease control patients had cases of gastric ulcer $(n=10)$, duodenal ulcer $(n=7)$, chronic gastritis $(n=5)$, gastric cancer $(n=5)$, gastric polyp $(n=3)$, enterocolitis $(n=4)$, ischemic colitis $(n=2)$, cholecystis $(n=5)$, alcoholic hepatitis $(n=1)$, liver cirrhosis $(n=3)$, pancreatic cancer $(n=2)$, thyroid adenoma $(n=2)$ and diabetes mellitus $(n=7)$. The diagnosis of asthma was made as previously described (Shimizu et al. 2006) according to the American Thoracic Society's definition of asthma (American Thoracic Society 1962). Asthmatic patients were excluded if they were pregnant or lactating, under 16 years of age, smokers, mentally incompetent, or had liver, kidney, or other severe diseases. Patients with a history of esophageal, gastric, or duodenal surgery were also excluded, and those being treated with an angiotensin-converting enzyme (ACE) inhibitor or a muscarine receptor antagonist were also excluded. Asthma severity was graded using the global strategy for asthma treatment and prevention (GINA) stated by the National Institute of Health (National Institute of Health, National Heart, Lung, and Blood Institute 2003). GINA classifies asthma status into general levels - mild, moderate, and severe - with the mild level being further divided into two levels. Briefly, level 1 is called the mild intermittent type with asthma symptoms appearing less than once a week and a peak expiratory flow (PEF) over $80 \%$ of predicted flow. Level 2 is called the mild continuous type with asthma symptoms appearing more than once a week, although not every day, and a PEF over $80 \%$ of predicted flow. Level 3 is called the moderate continuous type with asthma symptoms appearing every day and a PEF from $60 \%$ to $80 \%$ of predicted flow. Level 4 is called the severe continuous type with asthma symptoms worsening despite asthma treatment and a PEF less than $60 \%$ of predicted flow. Disease control patients were outpatients or patients admitted to the hospital due to the presence of diseases other than GERD. Cases of gastric ulcer, duodenal ulcer, chronic gastritis, gastric cancer, gastric polyps, and GERD were diagnosed after the patients were enrolled in this study. Healthy subjects were outpatients who had visited the hospital for a routine health examination; they had no disease but volunteered to undergo endoscopic examination. None of the patients was being treated with $\mathrm{H}_{2}$-blockers or PPIs as acid-suppressive drugs for GERD before endoscopic examination. The study was conducted according to the guidelines of the Declaration of Helsinki, and all patients gave written informed consent before enrollment in the study. Approval for the study was given by the Human Research Committee of Maebashi North Hospital and Gunma University Institution.

\section{Statistical analysis}

All values are shown as means \pm S.D. The differences between two groups in GERD grades and the frequency of GERD were tested using the $\mathrm{m} \times \mathrm{n}$ or $2 \times 2 \mathrm{Chi}$ square test, with Yates' test applied to adjust data where 
the sample number was $<10$. Statistical significance was set at $p<0.05$.

\section{Results}

The frequencies of LA classification grades for asthmatic patients, disease control patients, and healthy subjects are shown in Table 1 . The frequency of GERD of grade $\geqq$ A was: $47 / 284$ $(16.5 \%)$ overall; $37 / 78(47.4 \%)$ in the asthmatic patients; $4 / 56(7.2 \%)$ in the disease control patients; and $6 / 150(4 \%)$ in the healthy subjects.
The frequency of GERD of grade $\geqq$ M was: 98/284 (34.5\%) overall; 54/78 (69.2\%) in the asthmatic patients; $17 / 56(30.4 \%)$ in the disease control patients; and 27/150 (18\%) in the healthy subjects. The frequency of GERD of grade $\geqq M$ was significantly higher than that of grade $\geqq A$ in all group of asthmatic patients, disease control patients, and healthy subjects $(p<0.05)$ (Fig. 1). The frequency of GERD, both grade $\geqq A$ and grade $\geqq M$, was significantly higher in asthmatic patients than in disease control patients and

TABle 1. Frequency of GERD in asthmatic patients, disease control patients, and healthy subjects, classified by endoscopic LA classification with grade $\mathrm{M}$ of minimal change.

\begin{tabular}{ccccc}
\hline LA classification & Asthmatic patients $(\%)$ & $\begin{array}{c}\text { Disease control } \\
\text { patients }(\%)\end{array}$ & Healthy subjects (\%) & Total patients (\%) \\
\hline N & $24(30.8)$ & $39(69.6)$ & $123(82.0)$ & $186(65.5)$ \\
M & $17(21.8)$ & $13(23.2)$ & $21(14.0)$ & $51(18.0)$ \\
A & $22(28.2)$ & $3(5.4)$ & $1(0.7)$ & $26(9.2)$ \\
B & $11(14.1)$ & $1(1.8)$ & $2(1.3)$ & $14(4.9)$ \\
C & $2(2.6)$ & $0(0)$ & $3(2.0)$ & $5(1.8)$ \\
D & $2(2.6)$ & $0(0)$ & $0(0)$ & $2(0.7)$ \\
\hline
\end{tabular}

LA classification with minimal change was composed of grades $\mathrm{N}$ to $\mathrm{D}$, with $\mathrm{D}$ the most severe grade. Each column indicates patient number $(\%)$.

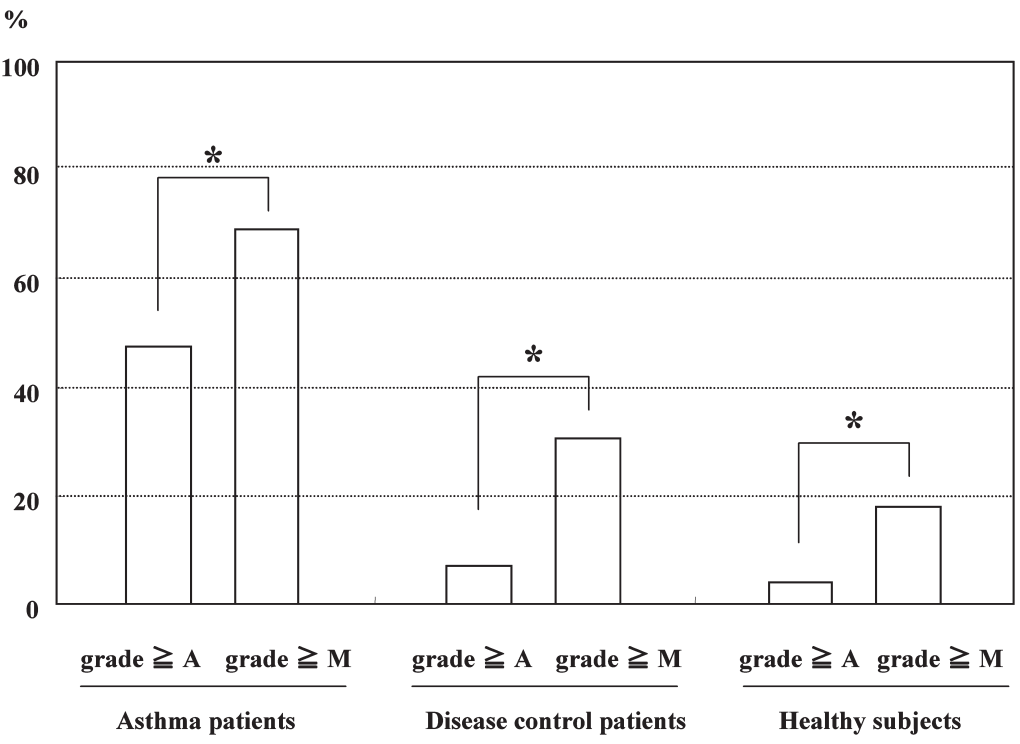

Fig. 1. Comparison of the GERD frequencies between grade $\geqq A$ and grade $\geqq M$ in asthmatic patients, disease control patients, and healthy subjects. Statistically significant differences between grade $\geqq$ A and grade $\geqq \mathrm{B}$ are expressed by $p<0.05$. LA classification with grade $\mathrm{N}$ to $\mathrm{D}$ was used to evaluate GERD frequency. 
healthy subjects $(p<0.05)$ (Fig. 2). Asthma severity in each of the LA grades is shown in Table 2. Moderate asthma was most frequent in grade $\mathrm{M}$; however, severe asthma was most frequent in grade A. The QUEST score was obtained in 134 patients and compared between asthmatic patients $(n=78)$ and disease control patients $(n=56)$. A QUEST score $\geqq 4$ was obtained in 59/78 asthmatic patients (75.6\%) and in 12/56 disease control patients $(21.4 \%)$. The QUEST score showed that asthmatic patients had a significantly higher frequency of GERD than disease control patients $(p<0.05)$ (Table 3$)$. The patient characteristics for each group were not significantly different in age and gender.
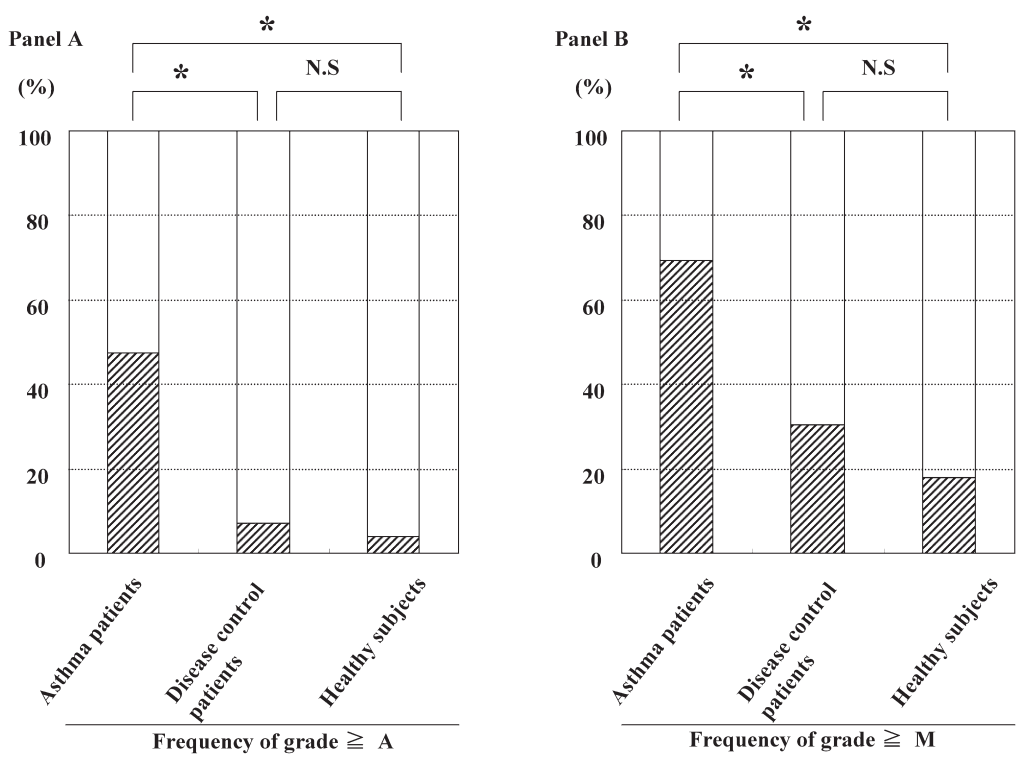

Fig. 2. Comparison of GERD frequencies in grade $\geqq A$ or grade $\geqq M$ among asthmatic patients, disease control patients, and healthy subjects. The meshed box indicates the frequencies of patients with grade $\geqq A($ panel $A)$ and grade $\geqq M$ (panel B). Statistically significant differences between groups are expressed by $p<0.05$. LA classification with or without minimal change of grade $\mathrm{M}$ was used to evaluate GERD frequency.

TABLE 2. Distribution of patient numbers classified by asthma severity for each LA grade.

\begin{tabular}{crrrr}
\hline Asthma severities & Mild & Moderate & Severe & Total $(n=78)$ \\
\hline LA classification with grade M & & & & \\
N & 4 & 7 & 13 & 24 \\
M & 3 & 11 & 3 & 17 \\
A & 2 & 6 & 14 & 22 \\
B & 3 & 5 & 3 & 11 \\
C & 1 & 0 & 1 & 2 \\
D & 1 & 1 & 0 & 2 \\
Total $(n=78)$ & 14 & 30 & 34 & 78 \\
\hline
\end{tabular}

Endoscopic GERD severities are shown by LA classification with minimum change. Asthma severities were classified according to the global strategy for asthma treatment and prevention (GINA) stated by the National Institute of Health. 
TABLE 3. GERD prevalence evaluated by the QUEST score on asthmatic patients and disease control patients.

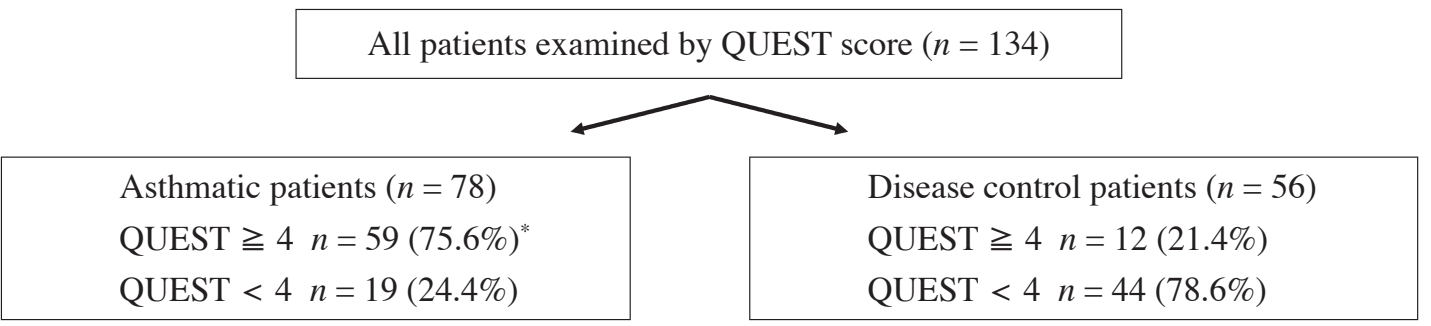

The QUEST score was used to assess GERD prevalence. A QUEST score $\geqq 4$ was diagnostic of GERD. Statistical confidence between the asthmatic patient group and the disease control group in QUEST $\geqq 4$ was expressed by ${ }^{*} p<0.05$.

\section{Discussion}

We found that the prevalence of GERD with grade $\geqq \mathrm{M}$ of endoscopic examination was $69.2 \%$ in asthma patients. The frequency of GERD of grade $\geqq \mathrm{M}$ in asthmatic patients was $21.8 \%$ higher than the frequency of GERD of grade $\geqq A$ (Fig. 1). The use of the LA classification without minimum change to diagnose GERD in asthmatic patients appears to underestimate the prevalence of GERD in such patients. The GERD frequency in asthmatic patients, when calculated by grade $\geqq A$ or grade $\geqq \mathrm{M}$, was higher than in non-asthmatic disease control patients and healthy subjects (Fig. 2). Asthmatic patients had a higher frequency of GERD than other groups using both the method of erosive lesions (established LA classification) and the method that includes non-erosive minimal change (LA classification with grade M). The GERD frequency, as measured by the QUEST score, was also higher in asthmatic patients than in disease control patients (Table 3). Moderate asthma was most frequent in grade $\mathrm{M}$; however, severe asthma was most frequent in grade A (Table 2).

Overall, on endoscopic examination, approximately $20 \%$ of all subjects (asthmatic patients, disease control patients, and healthy subjects) showed grade $\mathrm{M}$ findings (Table 1). Hoshihara (Hoshihara and Hashimoto 2000) examined subjects who did not have an abdominal surgery history, esophageal cancer, or achalasia and found that $27.1 \%$ of them had grade $\mathrm{M}$ findings. Recent studies dealing with the prevalence of GERD in asthmatic patients based on endoscopic examination did not include grade M (Harding 2003a, b) and there are no studies about the prevalence of GERD using endoscopic examination including grade $\mathrm{M}$ in asthma patients. Data from the present study indicate that the prevalence of GERD in asthmatic patients is high and that the prevalence of GERD in asthmatic patients has been underestimated when examined by endoscopy without including grade M. It is possible for the endoscopist to determine the minimal change of grade $\mathrm{M}$ using normal endoscopy, although magnifying endoscopes have recently been shown to be useful for the identification of minimal change (Kiesslich et al. 2004). The use of a magnifying endoscope might contribute to reducing the underestimation of endoscopic GERD. In asthma severity in each of the LA grades, moderate asthma was most frequent in grade $\mathrm{M}$; however, severe asthma was most frequent in grade A. One feature of severe asthma is persistent asthma exacerbation. Potential mechanisms to explain the relationship between asthma and GERD include microaspiration of acid into the airway (Tuchman et al. 1984). Because aspiration of acid into the airway could be caused by both grades $M$ and A of GERD, the more severe grade A of GERD seems to contribute to the persistence of asthma exacerbation rather than its trigger. In our study, GERD frequency evaluated by the QUEST score showed the maximum in asthmatic patients. On the other hand, GERD could be present in asthmatic patients even 
in the absence of GERD symptoms as determined by questionnaires (Harding et al. 2000). Although the presence of endoscopic GERD does not necessary correspond with the presence of GERD symptoms evaluated by the QUEST score, the minimal mucosal change denoted by grade $\mathrm{M}$ on endoscopy indicates that the patient has GERD. Although $\mathrm{H}_{2}$-blocker is a less effective acidsuppressor than PPIs (Chiba 1997), it has been reported that grade $\mathrm{M}$ esophagitis requires ondemand $\mathrm{H}_{2}$-blocker treatment (Nakamura et al. 2005). It may be clearly determined when asthma patients have grade $M$ of GERD; however, it has not been determined whether minimal change of grade $M$ affects asthma symptoms and also whether treatment for minimal change of GERD improves asthma. There were reports that asthma medicine of corticosteroid, theophylline, or $\beta 2$-agonist had a possibility of inducing GERD (Stein et al. 1980; Schindlbeck et al. 1988; Lazenby et al. 2002); however, it has not been determined whether these asthma medicines induce grade $\mathrm{M}$ of GERD. Further investigations are needed to evaluate the impact of minimal change of GERD on asthma.

In conclusion, our study showed that approximately $20 \%$ of asthmatic patients had grade M GERD on endoscopy. To avoid underestimation of GERD in asthmatic patients when using endoscopy, it is necessary to carefully identify minimal esophageal mucosal changes.

\section{Acknowledgments}

This study was not supported by any grants.

\section{References}

American Thoracic Society (1962) Definition and classification of chronic bronchitis, asthma, and pulmonary emphysema. Am. Rev. Respir. Dis., 85, 762-768.

Armstrong, D., Bennett, J.R., Blum, A.L., Dent, J., De Dombal, F.T., Galmiche, J.P., Lundell, L., Margulies, M., Richter, J.E., Spechler, S.J., Tygat, G.N. \& Wallin, L. (1996) The endoscopic assessment of esophagitis: a progress report on observer agreement. The endoscopic assessment of esophagitis: a progress report on observer agreement. Gastroenterology, 111, 85-92.

Carlsson, R., Dent, J., Bolling-Sternevald, F., Johnsson, F., Johnsson, F., Junghard, O., Lauritsen, K., Riley, S. \& Lundell, L. (1998) The usefulness of a structured question- naire in the assessment of symptomatic gastroesophageal reflux disease. Scand J. Gastroenterol., 33, 1023-1029.

Chiba, N. (1997) Proton pump inhibitors in acute healing and maintenance of erosive or worse esophagitis: a systematic overview. Can. J. Gastroenterol., 11, 66B-73B. (Review)

DeVault, K.R. \& Castell, D.O. (1995) Guidelines for the diagnosis and treatment of gastroesophageal reflux disease. Practice Parameters Committee of the American College of Gastroenterology. Arch. Intern. Med., 155, 2165-2173.

Harding, S.M., Guzzo, M.R. \& Richter, J.E. (1999) 24-h esophageal $\mathrm{pH}$ testing in asthmatics: respiratory symptom correlation with esophageal acid events. Chest, $\mathbf{1 1 5}$, 654-659.

Harding, S.M., Guzzo, M.R. \& Richter, J.E. (2000) The prevalence of gastroesophageal reflux in asthma patients without reflux symptoms. Am. J. Respir. Crit. Care Med., 162, 34-39.

Harding, S.M. (2003a) Acid reflux and asthma. Curr. Opin. Pulm. Med., 9, 42-45.

Harding, S.M. (2003b) Recent clinical investigations examining the association of asthma and gastroesophageal reflux. Am. J. Med., 115, 39S-44S. (Review)

Hoshihara, Y. \& Hashimoto, M. (2000) Endoscopic classification of reflux esophagitis. Nippon Rinsho, 58, 1808-1812.

Ichinose, M. (2003) Inflammatory mechanisms in bronchial asthma and COPD. Tohoku J. Exp. Med., 200, 1-6.

Kiesslich, R., Kanzler, S., Vieth, M., Moehler, M., Neidig, J., Thanka Nadar, B.J., Schilling, D., Burg, J., Nafe, B., Neurath, M.F. \& Galle, P.R. (2004) Minimal change esophagitis: prospective comparison of endoscopic and histological markers between patients with non-erosive reflux disease and normal controls using magnifying endoscopy. Dig. Dis., 22, 221-227.

Kiljander, T.O., Harding, S.M., Field, S.K., Stein, M.R., Nelson, H.S., Ekelund, J., Illueca, M., Beckman, O. \& Sostek, M.B. (2006) Effects of esomeprazole $40 \mathrm{mg}$ twice daily on asthma: a randomized placebo-controlled trial. Am. J. Respir. Crit. Care Med., 173, 1091-1097.

Lazenby, J.P., Guzzo, M.R., Harding, S.M., Patetrson, P.E., Johnson, L.F. \& Bradley, L.A. (2002) Oral corticosteroids increase esophageal acid contact times in patients with stable asthma. Chest, 121, 625-634.

Lundell, L.R., Dent, J., Bennett, J.R., Blum A.L., Armstrong, D., Galmiche, J.P., Johnson, F., Hongo, M., Richter, J.E., Spechler, S.J., Tytgat, G.N. \& Wallin, L. (1999) Endoscopic assessment of oesophagitis: clinical and functional correlates and further validation of the Los Angeles classification. Gut, 45, 172-180.

National Institute of Health, National Heart, Lung, and Blood Institute (2003) Global strategy for asthma treatment and prevention (GINA).

Nakamura, T., Shirakawa, K., Masuyama, H., Sugiyama, H., Hiraishi, H. \& Terano, A. (2005) Minimal change oesophagitis: a disease with characteristic differences to erosive oesophagitis. Aliment Pharmacol Ther., 21, 19-26.

Ricciardolo, F.L., Gaston, B. \& Hunt, J. (2004) Acid stress in the pathology of asthma. J. Allergy Clin. Immunol., 113 , 610-619.

Schindlbeck, N.E., Heinrich, C., Huber, R.M. \& Muller-Lissner, S.A. (1988) Effects of albuterol (salbutamol) on esophageal motility and gastroesophageal reflux in healthy volunteers. JAMA, 260, 3156-3158.

Shimizu, Y., Dobashi, K., Kobayashi, S., Ohki, I., Tokushima, M., Kusano, M., Kawamura, O., Shimoyama, Y., Utsugi, 
M., Sunaga, N., Ishizuka, T. \& Mori, M. (2006) A proton pump inhibitor, lansoprazole, ameliorates asthma symptoms in asthmatic patients with gastroesophageal reflux disease. Tohoku J. Exp. Med., 209, 181-189.

Shimoyama, Y., Kusano, M., Sugimoto, S., Kawamura, O., Maeda, M., Minashi, K., Kuribayashi, S., Higuchi, T., Zai, H., Ino, K., Horikoshi, T., Moki, F., Sugiyama, T., Toki, M., Ohwada, T. \& Mori, M. (2005) Diagnosis of gastroesophageal reflux disease using a new questionnaire. J. Gastroenterol. Hepatol., 20, 643-647.

Sontag, S.J., O'Connell, S., Khandelwal, S. \& Greenlee, H.
(2003) Asthmatics with gastroesophageal reflux: long term results of a randomized trial of medical and surgical antireflux therapies. Am. J. Gastroenterol., 98, 987-999.

Stein, M.R., Towner, T.G. \& Weber, R.W., Mansfield, L.E., Jacobson, K.W., Mcdonnell, J.T. \& Nelson, H.S. (1980) The effect of theophylline on the lower esophageal sphincter pressure. Ann. Allergy, 45, 238-241.

Tuchman, D.N., Boyle, J.T., Pack, A.l., Schwartz, J., Kokonos, M., Spitzer, A.R. \& Cohen, S. (1984) Comparison of airway responses following tracheal or esophageal acidification in the cat. Gastroenterology, 87, 872-881. 